\title{
Inferring relationships between health and fertility in Norwegian Red cows using recursive models
}

\author{
B. Heringstad, ${ }^{*} \dagger^{1} X .-L$. Wu, $\ddagger$ and D. Gianola ${ }^{*} \ddagger$ \\ *Department of Animal and Aquacultural Sciences, Norwegian University of Life Sciences, PO Box 5003, N-1432 Ås, Norway \\ †Geno Breeding and A. I. Association, PO Box 5003, N-1432 Ås, Norway \\ ‡Department of Dairy Science, University of Wisconsin, Madison 53706
}

\section{ABSTRACT}

Health and fertility are complex traits, and the phenotype for one trait may affect the phenotype of one or more other traits. For instance, disease in early lactation may impair a cow's ability to show estrus and to conceive after insemination. The objectives of the present study were to explore phenotypic and genetic relationships among health and fertility traits in Norwegian Red cows using a recursive effects model, which allows disentangling causal effects of phenotypes from the genetic and environmental correlations among traits. Records of interval from calving to first insemination (CFI), nonreturn rate within $56 \mathrm{~d}$ after first insemination (NR56), clinical mastitis (CM), ketosis (KET), and retained placenta from 55,568 first-lactation daughters of 1,577 Norwegian Red sires were analyzed. Trivariate recursive Gaussian-threshold models were used to analyze the 2 fertility traits (CFI and NR56) together with 1 disease trait in each analysis. The estimated structural coefficients of the recursive models imply that presence of KET or retained placenta lengthened CFI, whereas causal effects from CM to fertility were negligible. Recursive effects of disease on NR56, and of CFI on NR56, were all close to zero. Genetic correlations between health and fertility traits were low or moderate. The strongest genetic correlation was between KET and CFI (0.29), whereas genetic correlations between CM and NR56 and between CFI and NR56 were nil. In general, selection against disease is expected to slightly improve fertility (shorter CFI and higher NR56) as a correlated response and vice versa. The present results suggest that the use of structural-equation models, such as the one used here, may enhance our understanding of complex relationships among traits.

Key words: causal effect, health, fertility, recursive model

Received July 8, 2008.

Accepted November 26, 2008.

${ }^{1}$ Corresponding author: bjorg.heringstad@umb.no

\section{INTRODUCTION}

Many health and fertility traits may be viewed as resulting from complex relationships among phenotypes. For example, disease in early lactation may affect both a cow's ability to show estrus and to conceive after insemination. Structural-equation models represent a class of statistical specifications where the main objective is to introduce causal pathways. Causal relationships between phenotypes may be simultaneous (mutual) or recursive (i.e., one variable affects the other but the reciprocal effect does not exist). Gianola and Sorensen (2004) extended quantitative genetics models to handle situations in which there are simultaneous or recursive effects among phenotypes in a multivariate system. Wu et al. (2007, 2008) developed software for a Bayesian implementation, via Markov chain Monte Carlo methods, of such models. Varona et al. (2007) showed that recursive models can be interpreted as alternative parameterizations of standard linear models. The 2 models provide different interpretation of the results but are statistically equivalent.

Both health and fertility are complex traits, and so are their interrelationships. Some studies report favorable genetic correlations between health and fertility (Kadarmideen et al., 2000; Zwald et al., 2004; Heringstad et al., 2006b), whereas others have estimated zero (Heringstad et al., 2006a) or unfavorable genetic correlations (Pryce et al., 1997). Andersen-Ranberg and Heringstad (2006) estimated genetic correlations among female fertility, mastitis, and protein yield in first-lactation Norwegian Red cows. These authors found low to moderate genetic correlations between mastitis and fertility; estimates were highest for number of mastitis cases with interval from calving to first insemination (0.23) and close to 0 between mastitis and nonreturn rate. They found that all genetic correlations between mastitis and fertility were favorable, in the sense that selection against mastitis is expected to result in a small, positive correlated response in fertility; a shorter interval from calving to first insemination; and fewer services to conception. 
Structural-equation models have been used to study relationships between birth weight and litter size in pigs (Varona et al., 2007), milk production and mastitis (Wu et al., 2008), milk yield and claw disorders (König et al., 2008), fertility and dystocia (López de Maturana et al., 2007), and gestation length, calving difficulties, and stillbirth (López de Maturana et al., 2008). But so far, there have been no applications to health and fertility in dairy cows. Thus, our objective was to explore phenotypic and genetic relationships among health and fertility in Norwegian Red using recursive models. The traits included were interval from calving to first insemination (CFI), nonreturn rate within $56 \mathrm{~d}$ after first insemination (NR56), clinical mastitis (CM), ketosis (KET), and retained placenta (RP). The 2 fertility traits represent measures of the cows' ability to show estrus (CFI) and to conceive (NR56), and CM, $\mathrm{KET}$, and RP are the 3 most frequent diseases among first-lactation cows.

\section{MATERIALS AND METHODS}

\section{Data}

Data was from the Norwegian Dairy Herd Recording System. The data set consisted of records from 55,568 first-lactation daughters of 1,577 Norwegian Red sires. Only first batch daughters (i.e., difference between birth year of sire and birth year of daughter $<6 \mathrm{yr}$ ) from sires with at least 50 daughters were included. First calving had to be from 1990 to 2004, and age at first calving from 20 to 40 mo. Only cows with observations for both disease and fertility traits were included. The data set was restricted further to include only cows from herd-5-yr classes with at least 15 first-lactation cows in the data set. Absence or presence of each of the 3 diseases was scored as 0 or 1 , respectively, based on whether or not the cow had at least 1 veterinary treatment recorded within the interval from $15 \mathrm{~d}$ before to $30 \mathrm{~d}$ after calving for $\mathrm{CM}$, from $15 \mathrm{~d}$ before to 120 $\mathrm{d}$ after calving for KET, and within the first $5 \mathrm{~d}$ after calving for RP. Mean frequencies were $10 \%$ CM, $4 \%$ KET, and 2\% RP. Double insemination was defined as a new insemination 0 to $5 \mathrm{~d}$ after the first. The NR56 was scored as 1 or 0 based on whether or not the cow had a second insemination (other than double inseminations) within $56 \mathrm{~d}$ after the first insemination. Mean NR56 was 0.67 . The CFI had to be between 20 and $210 \mathrm{~d}$ and had a mean (SD) of 77 (29) d. The pedigree file had 2,252 males, including the 1,577 sires with daughters in the data set.

\section{Recursive Gaussian-Threshold Model}

Trivariate recursive Gaussian-threshold models were used to analyze the 2 fertility traits (CFI and NR56) together with each of the disease traits. The threshold model, used for binary traits, postulates an underlying continuous variable, liability $(l)$, such that the observed categorical variable takes the value 1 if the liability is larger than a fixed threshold and 0 otherwise. For binary traits, the threshold and the residual variance are not identifiable; therefore, these parameters were set to 0 and 1, respectively. In matrix notation, the recursive Gaussian-threshold model can be written as:

$$
\left[\begin{array}{c}
\Lambda y_{1} \\
\Lambda y_{2} \\
. \ddot{y} \\
\Lambda y_{n}
\end{array}\right]=X \beta+Z_{h} h+Z_{s} s+e
$$

where $\Lambda=\left[\begin{array}{ccc}1 & -\lambda_{12} & -\lambda_{13} \\ -\lambda_{21} & 1 & -\lambda_{23} \\ -\lambda_{31} & -\lambda_{32} & 1\end{array}\right]$ is a matrix of structural coefficients among traits 1 (CFI), 2 (NR56), and 3 (disease), $\lambda_{i j}$, which describes the rate of change in trait $i$ with respect to trait $j$ (one of the mutual effects, e.g., $\lambda_{31}$ or $\lambda_{13}$, must be zero in the recursive model); $\mathbf{y}_{\mathbf{1}}$, $\mathbf{y}_{2}, \ldots, \mathbf{y}_{\mathbf{n}}$ are vectors of CFI observations and liabilities to NR56 and disease (CM, KET, or RP) for the $\mathrm{n}=$ 55,568 cows, for instance for cow 1 $\mathbf{y}_{\mathbf{1}}=\left[\begin{array}{lll}y_{C F I_{1}} & l_{N R 56_{1}} & l_{\text {disease }_{1}}\end{array}\right]^{\prime} ; \boldsymbol{\beta}$ is a vector of trait-specific systematic effects, including age at first calving for all traits, month-year of first calving (168 classes) for CFI, month-year of insemination (165 classes) and double insemination (2 classes) for NR56, and yearseason of calving for the disease traits; $\mathbf{h}$ is a vector of herd-5-yr of calving effects (2,909 levels); $\mathbf{s}$ is a vector of effects of the sire effects; e is a vector of residuals; and $\mathbf{X}, \mathbf{Z}_{\mathrm{h}}$, and $\mathbf{Z}_{\mathrm{s}}$ are the corresponding incidence matrices.

Age at first calving had 10 classes, in which $<23$ mo was the first class, $>30$ mo was the last class, and other classes were single months. Because the disease frequencies were low, well-known extreme category problems of the threshold model were alleviated by forming year-season of calving instead of month-year of calving classes. Each year was divided into 4 seasons: January-March, April-June, July-September, and October-December, and year-season of calving had 56 levels. Because the average herd size in Norway is small, herd-5-yr effects were used instead of herd-year.

Here, causal effects of disease on both fertility traits, and of CFI on NR56, were assumed, whereas reciprocal effects were assumed not to exist. Thus, the recursive effects model used postulates that liability to disease 
affects CFI $\left(\lambda_{13}\right)$, liability to disease affects liability to $\operatorname{NR56}\left(\lambda_{23}\right)$, CFI affects liability to NR56 $\left(\lambda_{21}\right)$, and all other $\lambda$ were set to be zero.

Prior Distributions. Structural coefficients and the elements of $\boldsymbol{\beta}$ were assigned multivariate normal prior distributions. Sire effects were assigned the multivariate normal prior distribution $\mathbf{s} \sim N\left(\mathbf{0}, \mathbf{G}_{0} \otimes \mathbf{A}\right)$, where $\mathbf{G}_{0}$ is the sire covariance matrix for the 3 traits and $\mathbf{A}$ is the matrix of additive genetic relationships among bulls. The prior distribution of the herd-5-yr effects was $\mathbf{h} \sim N\left(\mathbf{0}, \mathbf{H}_{0} \otimes \mathbf{I}\right)$, where $\mathbf{H}_{0}$ is the (co)variance matrix and $\mathbf{I}$ is an identity matrix. Independent inverse Wishart prior distributions were used for $\mathbf{H}_{0}$ and $\mathbf{G}_{0}$, the (co)variance matrices of $\mathbf{h}$ and $\mathbf{s}$, respectively. The prior distribution of the residual covariance matrix $\mathbf{R}$ was a conditional inverse Wishart distribution because the residual variances of the 2 binary traits were each set to 1 (Korsgaard et al., 2003).

System Parameters and Identifiability. Parameters from the recursive model differ from those of a mixed model and should be interpreted as system parameters (Gianola and Sorensen, 2004). To estimate covariance matrices $\mathbf{G}_{0}^{*}, \mathbf{H}_{0}^{*}$, and $\mathbf{R}_{0}^{*}$ pertaining to the standard mixed model, the following relationships were used:

$$
\begin{aligned}
& \mathbf{G}_{0}^{*}=\boldsymbol{\Lambda}^{-1} \mathbf{G}_{0} \boldsymbol{\Lambda}^{\prime-1} \\
& \mathbf{H}_{0}^{*}=\boldsymbol{\Lambda}^{-1} \mathbf{H}_{0} \boldsymbol{\Lambda}^{\prime-1} \\
& \mathbf{R}_{0}^{*}=\boldsymbol{\Lambda}^{-1} \mathbf{R}_{0} \boldsymbol{\Lambda}^{\prime-1} .
\end{aligned}
$$

Heritability and correlations were calculated from $\mathbf{G}_{0}^{*}, \mathbf{H}_{0}^{*}$, and $\mathbf{R}_{0}^{*}$ in the usual manner.

The recursive model is not identifiable at the level of the likelihood because of the presence of extra parameters (i.e., structural coefficients). To attain identification, it was assumed that system residuals were uncorrelated. Thus, the standard residual correlations are explained in terms of structural coefficients.

Sampling and Convergence Diagnostics. Bayesian analysis via Markov chain Monte Carlo methods (Sorensen and Gianola, 2002) as implemented by Wu et al. $(2007,2008)$ was used. The SirBayes package (Wu et al., 2008) was used for analysis. Draws from the posterior distributions of the parameters were obtained using Gibbs sampling. Based on trace plots and the convergence diagnostics method of Raftery and Lewis (1992), it was decided to discard the first 5,000 iterations as burn-in and thereafter use a total chain length of 50,000 for analyses involving CM and KET and a total chain length of 70,000 for the analysis of fertility and RP. All samples after burn-in were used for posterior inferences.

\section{Linear Model Analysis}

For comparison, the data were also analyzed with trivariate linear (nonrecursive) sire models using the AI-REML procedure in the DMU package (Madsen and Jensen, 2008), ignoring the binary nature of the traits and possible recursive effects among phenotypes. The fixed and random effects for each trait were as described above.

\section{RESULTS AND DISCUSSION}

Mean CFI and NR56 for cows in each of the disease categories are in Table 1. The phenotypic frequencies show that cows with KET had the longest CFI and the lowest NR56. Also, cows with RP had longer CFI and lower NR56 than the average. Cows with mastitis had the best fertility (shortest CFI and highest NR56) but the highest frequency of KET as well as RP.

\section{Recursive Effects}

Posterior distributions of the recursive effects of liability to disease on CFI are in Figure 1. The distributions were symmetric, with posterior mean 0.20 (KET), $0.17(\mathrm{RP})$, and $-0.03(\mathrm{CM})$, all with posterior SD 0.12 (Table 2). Although the value 0 entered the distributions at an appreciable density (Figure 1), results suggest that an increased liability to KET or RP elevates CFI, whereas CM has a negligible effect on CFI.

As shown in Figure 2, the posterior distributions of the recursive effects from liability to disease to NR56 overlapped substantially and included zero with high density. Posterior means (SD) ranged from -0.004 (0.03) to 0.01 (0.03) (Table 2). The posterior mean of the recursive effects of CFI to liability on NR56 was close to zero in all 3 analyses (Table 2).

The generally good fertility level and low disease frequency in Norwegian Red (Table 1) should be kept in mind when interpreting these results. Causal effects among phenotypes may be different in situations with poor fertility, health, or both.

The effect of disease on fertility may result from altered reproductive function in diseased cows (e.g., delayed estrus) and from farmers decisions (e.g., to postpone service to allow the diseased cow to recover). Both delayed estrus and postponed first service would affect CFI but would probably to a lesser degree affect NR56. The effect of KET on fertility may be related to energy 
Table 1. Mean interval from calving to first insemination (CFI), nonreturn within $56 \mathrm{~d}$ (NR56), and disease frequencies for cows with absence (0) or presence (1) of clinical mastitis $(\mathrm{CM})$, ketosis $(\mathrm{KET})$, and retained placenta (RP)

\begin{tabular}{|c|c|c|c|c|c|c|c|}
\hline \multirow[b]{2}{*}{ Item } & \multirow[b]{2}{*}{ Overall mean } & \multicolumn{2}{|c|}{$\mathrm{CM}$} & \multicolumn{2}{|c|}{ KET } & \multicolumn{2}{|c|}{$\mathrm{RP}$} \\
\hline & & 0 & 1 & 0 & 1 & 0 & 1 \\
\hline NR56 & 0.67 & 0.67 & 0.68 & 0.67 & 0.63 & 0.67 & 0.65 \\
\hline $\mathrm{CM}$ & 0.10 & & & 0.10 & 0.14 & 0.10 & 0.15 \\
\hline KET & 0.04 & 0.04 & 0.05 & & & 0.04 & 0.05 \\
\hline $\mathrm{RP}$ & 0.02 & 0.02 & 0.03 & 0.02 & 0.03 & & \\
\hline
\end{tabular}

balance. Ketosis is caused by imbalance in the cow's energy metabolism, a result of lipid mobilization and carbohydrate insufficiency (Baird, 1982). Associations of calculated negative energy balance with reproductive traits, including days to first luteal activity and days from calving to first AI service, have been reported in several studies (Villa-Godoy et al., 1988; Staples et al., 1990).

\section{Heritabilities}

Posterior distributions of heritability of CFI and of liability to NR56, CM, KET, and RP are in Figure 3. The distribution for CFI was sharp and symmetric, whereas the distributions of heritability for NR56 and the 3 diseases had larger posterior standard deviation.

Posterior means (SD) of variance components and of heritabilities are in Table 3. The heritabilities of liability to CM (0.07), KET (0.09), and RP (0.09) were within the range of previous threshold model estimates of heritability of these diseases (Zwald et al., 2004; Heringstad et al., 2005). The heritability of CFI (0.04) was also in agreement with previously published estimates, whereas the heritability of liability to NR56 (0.06) was higher, but with a large standard deviation. AndersenRanberg (2005) found that heritability estimates in the literature range between 3.0 and $4.0 \%$ for CFI and between 2.2 and $3.5 \%$ for liability of nonreturn rate.

\section{Genetic Correlations}

The posterior distributions of the genetic correlations with the highest (KET and CFI) and lowest (KET and NR56) mean and the highest (CFI and NR56) and lowest (CM and NR56) standard deviation are given in Figure 4. Posterior means and standard deviations of genetic correlations are in Table 2. The posterior standard deviations were large and results should therefore be interpreted with caution.

The strongest genetic correlations were found for KET with fertility, with genetic correlations of 0.29 with CFI and -0.23 with NR56. The latter is in the same direction as the correlation of -0.10 between PTA for daughter pregnancy rate (from USDA routine evaluation) and PTA for probability of KET reported by Zwald et al. (2004).

The genetic correlations of RP with fertility were positive. Estimates of genetic correlations of RP with CFI or NR56 were not available in the literature. Schnitzenlehner et al. (1998) estimated a genetic correlation of 0.54 between RP and days open in first lactation.

There was no significant genetic correlation between CM and NR56 in first lactation (Table 2), which is in agreement with previous studies based on Norwegian data (Andersen-Ranberg and Heringstad, 2006; Heringstad et al., 2006a). Other studies have reported negative correlations among similar traits. For example, Pryce

Table 2. Posterior mean and standard deviation of recursive effects and genetic and herd-5-yr (H5Y) correlations between interval from calving to first insemination (CFI), nonreturn within $56 \mathrm{~d}$ (NR56), clinical mastitis (CM), ketosis (KET), and retained placenta (RP)

\begin{tabular}{|c|c|c|c|c|c|c|}
\hline Traits & \multicolumn{2}{|c|}{ Recursive effect $^{1}$} & \multicolumn{2}{|c|}{ Genetic correlation } & \multicolumn{2}{|c|}{ H5Y correlation } \\
\hline CFI and NR56 ${ }^{2}$ & 0.005 & 0.02 & -0.01 & 0.30 & 0.35 & 0.27 \\
\hline $\mathrm{CM}$ and NR56 & 0.01 & 0.03 & -0.03 & 0.12 & -0.10 & 0.05 \\
\hline KET and CFI & 0.20 & 0.12 & 0.29 & 0.19 & 0.12 & 0.04 \\
\hline KET and NR56 & -0.003 & 0.03 & -0.23 & 0.20 & -0.10 & 0.08 \\
\hline
\end{tabular}

${ }^{1}$ First trait affects second trait.

${ }^{2}$ Results from the 3 runs were very similar and only results from the model with KET are given. 


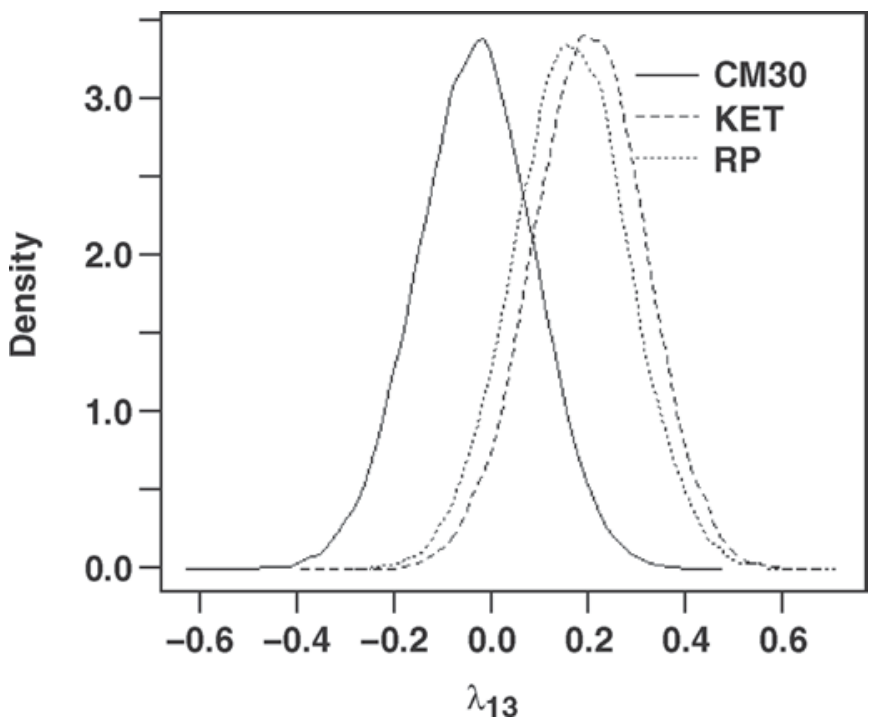

Figure 1. Posterior distributions of recursive effects from liability to disease $\left(\mathrm{CM}, \mathrm{KET}\right.$, or RP) to $\mathrm{CFI}\left(\lambda_{13}\right)$. $\mathrm{CM}=$ clinical mastitis; $\mathrm{KET}=$ ketosis; $\mathrm{RP}=$ retained placenta; $\mathrm{CFI}=$ interval from calving to first insemination.

et al. (1998) and Kadarmideen et al. (2000) reported genetic correlations between mastitis and conception rate to first service of -0.58 and -0.21 , respectively, for Holstein cattle in the United Kingdom.

The genetic correlation between NR56 and CFI was near 0 (Table 2), which is in agreement with previous estimates (Andersen-Ranberg and Heringstad, 2006). The lack of correlation reflects that these traits represent 2 independent aspects of fertility. The CFI measures the cow's ability to come into estrus and show heat, and NR56 is a measure of the ability to conceive after insemination.

Here, we analyzed a relatively small data set, and the genetic correlations involving diseases with low frequencies were not estimated precisely. However, despite the large posterior standard deviation, results corroborated the existence of favorable genetic correlations of health with fertility. All genetic correlations (Table 2), except the one between RP and NR56, were favorable, in the sense that selection against disease is expected to result in favorable correlated responses in fertility, for example as shorter CFI and higher NR56, and vice versa.

\section{Environmental Correlations}

Posterior mean and SD of correlations among herd-5yr effects are given in Table 2. The correlations among herd-5-yr effects indicate that herds with high KET tend to have longer CFI and lower NR56 than herds with less KET. Herds with high RP tend to have longer CFI and higher NR56 than the average. A positive herd-

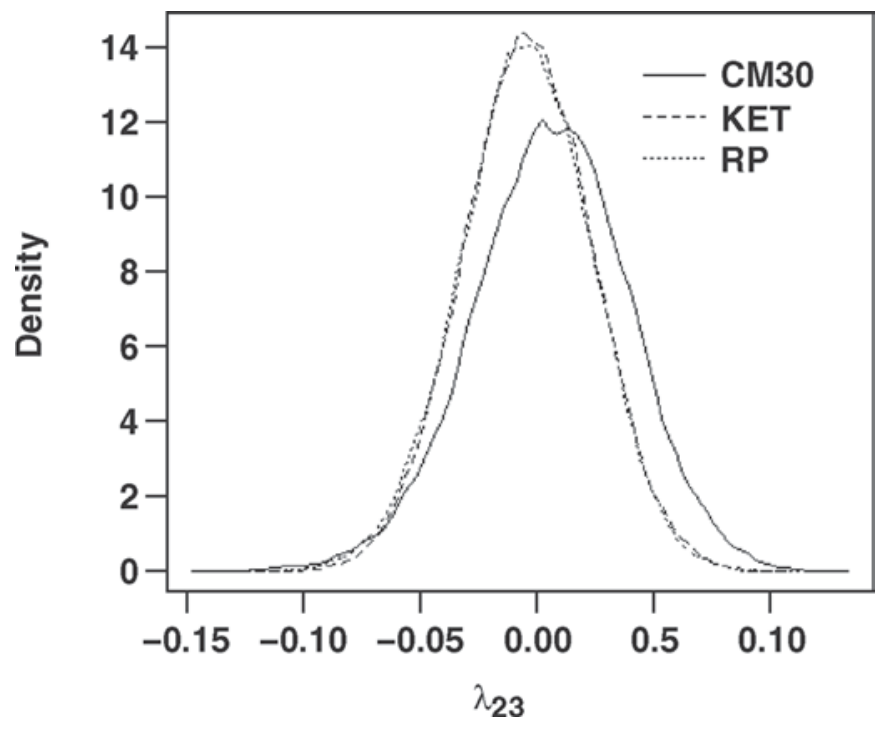

Figure 2. Posterior distributions of recursive effects from liability to disease $\left(\mathrm{CM}, \mathrm{KET}\right.$, or RP) to NR56 $\left(\lambda_{23}\right) . \mathrm{CM}=$ clinical mastitis; $\mathrm{KET}=$ ketosis; $\mathrm{RP}=$ retained placenta; $\mathrm{NR} 56=$ nonreturn within $56 \mathrm{~d}$.

5-yr correlation between CFI and NR56 (0.35) suggests that herds with longer CFI tend to have higher NR56.

\section{Linear Model Estimates}

For comparison, linear model estimates of genetic, herd-5-yr, and residual correlations are in Table 4. Residual correlations of fertility with the 3 disease traits

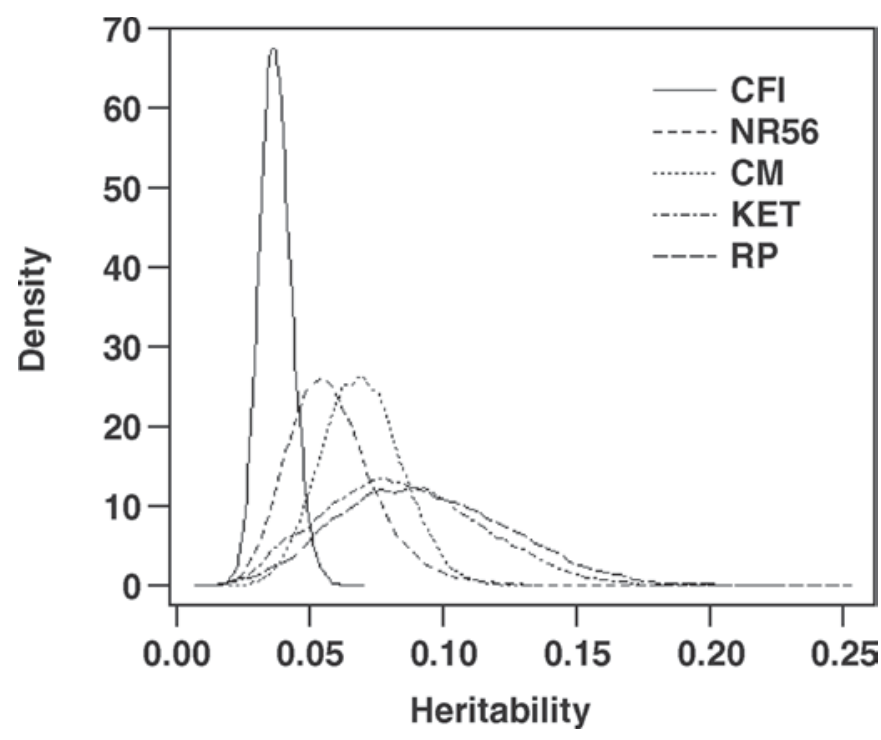

Figure 3. Posterior distributions of (from the left) heritability of CFI and of liability to NR56, CM, KET, and RP. CFI = interval from calving to first insemination; $\mathrm{CM}=$ clinical mastitis; $\mathrm{KET}=$ ketosis; $\mathrm{RP}=$ retained placenta; NR56 = nonreturn within $56 \mathrm{~d}$. 
Table 3. Posterior mean and standard deviation of sire and herd-5-yr variances and of heritability ${ }^{1}$ of interval from calving to first insemination (CFI), nonreturn within $56 \mathrm{~d}$ (NR56), clinical mastitis (CM), ketosis (KET), and retained placenta (RP)

\begin{tabular}{|c|c|c|c|c|c|c|}
\hline \multirow[b]{2}{*}{ Trait } & \multicolumn{2}{|c|}{ Sire variance } & \multicolumn{2}{|c|}{ Herd-5-yr variance } & \multicolumn{2}{|c|}{ Heritability } \\
\hline & Mean & $\mathrm{SD}$ & Mean & $\mathrm{SD}$ & Mean & $\mathrm{SD}$ \\
\hline $\mathrm{CFI}^{2}{ }^{2} \mathrm{~d}$ & 6.39 & 1.05 & 106.61 & 4.21 & 0.04 & 0.006 \\
\hline $\mathrm{CM}$ & 0.018 & 0.004 & 0.14 & 0.01 & 0.07 & 0.01 \\
\hline KET & 0.022 & 0.008 & 0.38 & 0.03 & 0.09 & 0.03 \\
\hline $\mathrm{RP}$ & 0.024 & 0.009 & 0.03 & 0.02 & 0.09 & 0.03 \\
\hline
\end{tabular}

${ }^{1}$ Heritability: $\mathrm{h}^{2}=4 \sigma_{\mathrm{s}}^{2} / \sigma_{\mathrm{s}}^{2}+\sigma_{\mathrm{e}}^{2}$, where $\sigma_{\mathrm{s}}^{2}=$ sire variance and $\sigma_{\mathrm{e}}^{2}=$ residual variance.

${ }^{2}$ Results from the 3 runs were very similar and only results from the model with KET are given.

were all negligible, ranging from -0.02 to 0.01 . In spite of large standard errors, especially for the genetic correlations, there was a generally good agreement between linear model estimates of genetic and herd-5-yr correlations (Table 4) and the posterior mean of the corresponding correlations from the recursive model (Table 2).

\section{Model Assumptions and Limitations}

Only cows with observations for both disease and fertility were included in this study. Excluding cows that were culled without having an insemination may have caused some selection bias because cows with disease in early lactation have a higher risk than healthy cows of being culled. Strategies for including cows with

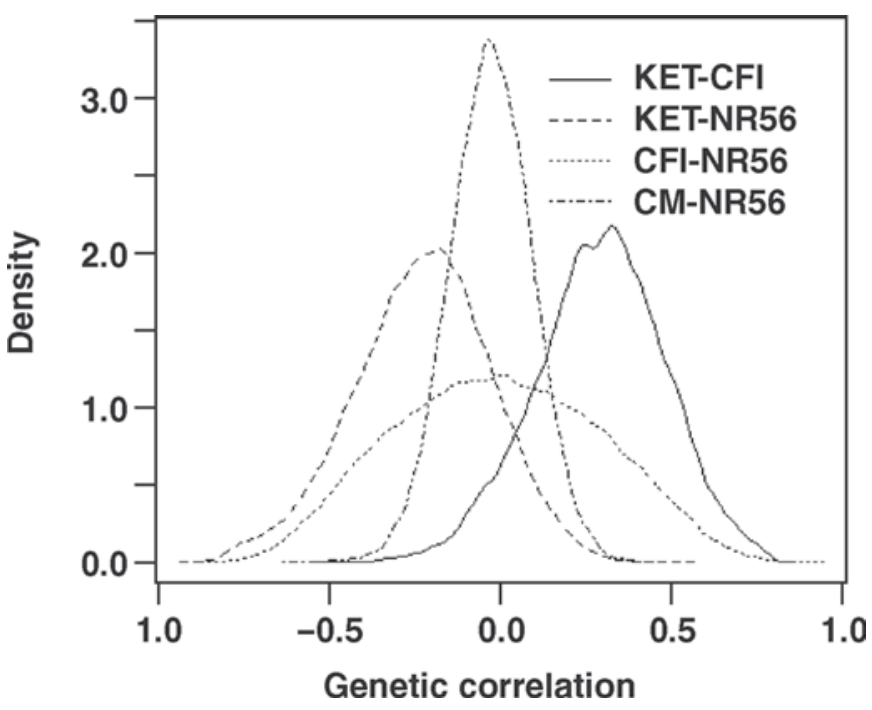

Figure 4. Genetic correlations between health and fertility. The posterior distributions with the highest (KET-CFI) and lowest (KETNR56) mean and the highest (CFI-NR56) and lowest (CM-NR56) standard deviation are shown. $\mathrm{CFI}=$ interval from calving to first insemination; $\mathrm{CM}=$ clinical mastitis; $\mathrm{KET}=$ ketosis; $\mathrm{RP}=$ retained placenta; NR56 = nonreturn within $56 \mathrm{~d}$. missing or censored records for 1 or more traits may be a subject for future improvements of the software.

Service sire was not included in the models for fertility. This was based on results of Andersen-Ranberg et al. (2003), who found that service sire accounted for a very small fraction of the variation of fertility in Norwegian Red.

Here, we assumed recursive effects from disease to both fertility traits and from CFI to NR56. Simultaneous effects would not make sense for the traits analyzed here but could be sensible for other health and fertility traits.

Because of computing limitations, the 2 fertility traits were analyzed together with only one of the diseases in each analysis. Possible causal effects among the diseases were therefore not examined. Expanding the analysis to include more traits and more causal relationships will be subjects for future studies.

\section{CONCLUSIONS}

Positive structural coefficients imply that increased liability to KET or RP elevates CFI, whereas negligible causal effects were revealed from mastitis to fertility. Recursive effects from disease to NR56, and from CFI to NR56, were all close to zero. Genetic correlations between health and fertility were low to moderate, and selection against disease is expected to result in a small improvement of fertility as a correlated response.

Use of structural-equation models allowed distinguishing between causal effects between phenotypes and the genetic relationship between traits, and such models may be useful to attain a better understanding of complex relationships between traits.

\section{ACKNOWLEDGMENTS}

Access to the data was given by the Norwegian Dairy Herd Recording System and the Norwegian Cattle Health Service (Ås, Norway) in agreement number 004.2005. This work is part of project no. 167893/ 
Table 4. Linear model estimates with standard errors (SE) of genetic, herd-5-yr (H5Y), and residual correlations between interval from calving to first insemination (CFI) and nonreturn within $56 \mathrm{~d}$ (NR56), and for those traits with clinical mastitis (CM), ketosis (KET), and retained placenta $(\mathrm{RP})$

\begin{tabular}{|c|c|c|c|c|c|c|}
\hline Traits & \multicolumn{2}{|c|}{ Genetic correlation } & \multicolumn{2}{|c|}{ H5Y correlation } & \multicolumn{2}{|c|}{ Residual correlation } \\
\hline CFI and NR5 $6^{1}$ & -0.03 & 0.15 & 0.44 & 0.04 & 0.06 & 0.004 \\
\hline CM and NR56 & 0.07 & 0.17 & -0.15 & 0.05 & 0.01 & 0.004 \\
\hline KET and CFI & 0.20 & 0.15 & 0.10 & 0.03 & 0.02 & 0.004 \\
\hline KET and NR56 & -0.34 & 0.19 & -0.11 & 0.04 & -0.01 & 0.004 \\
\hline
\end{tabular}

${ }^{1}$ Correlations from the 3 runs were very similar and only results from the model with KET are given.

I10 ("Avl for friskere kyr") financed by the Research Council of Norway (Oslo, Norway). Support was also received from the Babcock Institute for International Dairy Research and Development, University of Wisconsin, Madison. Support by the Wisconsin Agriculture Experiment Station, and by grant NSF DMS-NSF DMS-044371 is acknowledged.

\section{REFERENCES}

Andersen-Ranberg, I. M. 2005. Genetics of dairy cow fertility. PhD Thesis. Norwegian University of Life Sciences, Ås, Norway.

Andersen-Ranberg, I. M., and B. Heringstad. 2006. Genetic associations between female fertility, mastitis and protein yield in Norwegian Red. Proc. 8th WCGALP, Belo Horizonte, Brazil. CD-ROM communication no. 01-20.

Andersen-Ranberg, I. M., B. Heringstad, G. Klemetsdal, M. Svendsen, and T. Steine. 2003. Heifer fertility in Norwegian Dairy Cattle: Variance components and genetic change. J. Dairy Sci. 86:27062714

Baird, G. D. 1982. Primary ketosis in the high-producing dairy cow: Clinical and subclinical disorders, treatment, prevention, and outlook. J. Dairy Sci. 65:1-10.

Gianola, D., and D. Sorensen. 2004. Quantitative genetic models for describing simultaneous and recursive relationships between phenotypes. Genetics 167:1407-1424.

Heringstad, B., I. M. Andersen-Ranberg, Y. M. Chang, and D. Gianola. 2006a. Short communication: Genetic analysis of nonreturn rate and mastitis in first-lactation Norwegian Red cows. J. Dairy Sci. 89:4420-4423.

Heringstad, B., Y. M. Chang, I. M. Andersen-Ranberg, and D. Gianola. 2006b. Genetic analysis of number of mastitis cases and number of services to conception using a bivariate censored threshold model. J. Dairy Sci. 89:4042-4048.

Heringstad, B., Y. M. Chang, D. Gianola, and G. Klemetsdal. 2005. Genetic analysis of clinical mastitis, milk fever, ketosis, and retained placenta in three lactations of Norwegian Red cows. J. Dairy Sci. 88:3272-3281.

Kadarmideen, H. N., R. Thompson, and G. Simm. 2000. Linear and threshold model genetic parameters for disease, fertility and milk production in dairy cattle. Anim. Sci. 71:411-419.

König, S., X.-L. Wu, D. Gianola, B. Heringstad, and H. Simianer. 2008. Exploration of relationships between claw disorders and milk yield in Holstein cows via recursive linear and threshold models. J. Dairy Sci. 91:395-406.

Korsgaard, I. R., M. S. Lund, D. Sorensen, D. Gianola, P. Madsen, and J. Jensen. 2003. Multivariate Bayesian analysis of Gaussian, right censored Gaussian, ordered categorical and binary traits using Gibbs sampling. Genet. Sel. Evol. 35:159-183.
López de Maturana, E. L., A. Legarra, L. Varona, and E. Ugarte 2007. Analysis of fertility and dystocia in Holsteins using recursive models to handle censored and categorical data. J. Dairy Sci 90:2012-2024.

López de Maturana, E., X. L. Wu, D. Gianola, K. A. Weigel, and G. J. M. Rosa. 2008. Exploring biological relationships between calving traits in primiparous cattle with a Bayesian recursive model. Genetics 181:277-287.

Madsen, P., and J. Jensen. 2008. A User's Guide to DMU. A Package for Analyzing Multivariate Mixed Models. Version 6, release 4.7. Department of Genetics and Biotechnology, Research Centre Foulum, Tjele, Denmark.

Pryce, J. E., R. J. Esslemont, R. Thompson, R. F. Veerkamp, M. A. Kossaibati, and G. Simm. 1998. Estimation of genetic parameters using health, fertility and production data from a management recording system for dairy cattle. Anim. Sci. 66:577-584.

Pryce, J. E., R. F. Veerkamp, R. Thompson, W. G. Hill, and G. Simm. 1997. Genetic aspects of common health disorders and measures of fertility in Holstein Friesian dairy cattle. Anim. Sci. 65:353-360.

Raftery, A. L., and S. Lewis. 1992. How many iterations in the Gibbs sampler? Pages 763-774 in Bayesian Statistics 4. J. M. Bernando, J. O. Berger, A. P. Dawid, and A. F. M. Smith, ed. Oxford University Press, Oxford, UK.

Schnitzenlehner, S., A. Essel, and J. Solkner. 1998. Retained placenta: Estimation of nongenetic effects, heritability and correlations to important traits in cattle. J. Anim. Breed. Genet. 115:467-478.

Sorensen, D., and D. Gianola. 2002. Likelihood, Bayesian, and MCMC methods in quantitative genetics. Springer-Verlag, New York, NY.

Staples, C. R., W. W. Thatcher, and J. H. Clark. 1990. Relationship between ovarian activity and energy status during the early postpartum period of high producing dairy cows. J. Dairy Sci. 73:938-947.

Varona, L., D. Sorensen, and R. Thompson. 2007. Analysis of litter size and average weight in pigs using a recursive model. Genetics 177:1791-1799

Villa-Godoy, A., T. L. Hughes, R. S. Emery, L. T. Chapin, and R. L. Fogwell. 1988. Association between energy balance and luteal function in lactating dairy cows. J. Dairy Sci. 71:1063-1072.

Wu, X.-L., B. Heringstad, Y. M. Chang, G. de los Campos, and D. Gianola. 2007. Inferring relationships between somatic cell score and milk yield using simultaneous and recursive models. J. Dairy Sci. 90:3508-3521.

Wu, X.-L., B. Heringstad, and D. Gianola. 2008. Exploration of lagged relationships between mastitis and milk yield in dairy cows using a Bayesian structural equation Gaussian-threshold model. Gen. Sel. Evol. 40:333-357.

Zwald, N. R., K. A. Weigel, Y. M. Chang, R. D. Welper, and J. S. Clay. 2004. Genetic selection for health traits using producerrecorded data. I. Incidence rates, heritability estimates, and sire breeding values. J. Dairy Sci. 87:4287-4294. 